\title{
Prazer e sofrimento docente: estudo na pós-graduação stricto sensu
}

\author{
Chancarlyne Vivian ${ }^{1}$, Letícia de Lima Trindade ${ }^{2}$, \\ Carine Vendruscolo ${ }^{3}$
}

\footnotetext{
${ }^{1}$ http://orcid.org/0000-0003-3697-4109 - Universidade Comunitária da Região de Chapecó (UNOCHAPECO), Brasil

${ }^{2}$ http://orcid.org/0000-0002-7119-0230 - Universidade Comunitária da Região de Chapecó (UNOCHAPECO), Brasil; Universidade do Estado de Santa Catarina (UDESC), Brasil

${ }^{3}$ http://orcid.org/0000-0002-5163-4789 - Universidade do Estado de Santa Catarina (UDESC), Brasil
}

\section{Resumo}

Trata-se de um estudo descritivo, quantitativo-qualitativo, cujo objetivo é identificar as situações geradoras de estímulo e dificuldade no processo docente da pós-graduação stricto sensu. Participaram desta investigação acadêmica quarenta e sete professores de sete programas, que responderam ao Inventário sobre Trabalho e Riscos de Adoecimento e entrevista. Os processos de prazer e sofrimento docentes foram influenciados por: tempo de formação profissional, titulação, horas de jornada laboral e atuação como coordenador de curso. Os docentes recorrem ao uso de medicamentos para sanar o sofrimento, o qual é influenciado pela intensificação, sobrecarga e burocratização do trabalho, além da falta de diálogo, pressões organizacionais e dos limites do reconhecimento de seus esforços laborais. Por outro lado, as inter-relações, a possibilidade de transformar realidades e a própria identidade profissional promovem o prazer. Percebe-se que a distância entre o prazer e o sofrimento para docentes da pós-graduação é tênue, com repercussões na sua saúde física e psíquica.

Palavras-chave: prazer, sofrimento, docente, Psicodinâmica do Trabalho.

\section{Pleasure and suffering in teaching: a study in the stricto sensu graduate program}

Abstract

This is a descriptive study, quantitative and qualitative, whose objective was to identify the situations that generate pleasure and suffering for teaching staff in the postgraduate stricto sensu course. Forty seven teachers from seven programs participated, who responded to the Inventory on Work and Illness Risks, and an interview. Pleasure and suffering from teaching were influenced by aspects such as professional training time, degree held, number of hours worked, and whether or not the teacher acted as course coordinator. Many teachers resort to the use of medicines to mediate suffering, which is influenced by the intensification, overload, and bureaucratization of work, lack of dialogue, organizational pressures, and the limits of recognition. However, relationships, the possibility of transforming or influencing realities and professional identity are considered propellant aspects of pleasure at work. It is concluded that the distance between pleasure and suffering among postgraduate teaching staff is tenuous, with repercussions on their physical and psychological health.

Keywords: pleasure, suffering, faculty, Psychodynamics of Work.

\section{Placer y sufrimiento del profesor: un estudio en el programa de posgrado stricto sensu}

Resumen

Es um estudio descriptivo, cuantitativo-cualitativo, cuyo objetivo es identificar las situaciones que generan estímulos y dificultades en el proceso docente del graduado stricto sensu. Participaron de esta investigación académica cuarenta profesores miembros de la facultad de siete programas, quienes respondieron al Inventario sobre Riesgos Laborales y de Enfermedades y la entrevista. La investigación fue aprobada por el Comité de Ética de la institución. Los procesos de placer y el sufrimiento docentes estuvieron influenciados por aspectos tales como el tiempo de capacitación profesional, el grado, la cantidad de horas trabajadas y por actuar como coordinador del curso. Muchos maestros recurren al uso de medicamentos para sanar el sufrimiento. Esto fue influenciado por la intensificación, sobrecarga, burocratización del trabajo, falta de diálogo, presiones organizacionales y los límites del reconocimiento de sus esfuerzos laborales. Por otro lado, las interrelaciones, la posibilidad de transformar las realidades y de la propia identidad profesional se consideran aspectos propulsores del placer en el trabajo. Se percibe que la distancia entre el placer y el sufrimiento entre los profesores de posgrado es tenue, con repercusiones en su salud física y psicológica.

Palabras-clave: placer, sufrimiento, docente, Psicodinámica del Trabajo.

Como citar esse artigo: 
Os estudos contextualizam que trabalhar envolve constructos e representações. Independentemente dos sentimentos que podem ser despertados pelo trabalho, não há como esquivar-se do impacto gerado por ele sobre quem trabalha, tanto como indivíduos quanto como membros da sociedade (Dejours; Deranty; Renault, \& Smith, 2018). Nesse sentido, emergem as imposições e as pressões exercidas pela organização do trabalho, somadas às exigências de adaptação aos valores e à cultura organizacional, fatores que interferem no prazer e sofrimento do trabalhador (Dejours, 2015; Dejours, 2017; Dejours; Abdoucheli, \& Jayet, 2015; Dejours et al., 2018).

O referencial da Psicodinâmica do Trabalho defende que o prazer é extraído do sucesso do trabalho e está ligado à subjetividade do trabalhador. É um princípio mobilizador da dinâmica que emerge dos contextos laborais e pode ser resultado também das boas relações no ambiente laboral (Dejours, 2015). Pesquisas demonstram que suas fontes podem resultar da satisfação por executar uma tarefa prescrita, da qualidade nas relações interpessoais, da organização do trabalho e do resultado de vivências simbolizadas positivamente pelos indivíduos em seu exercício profissional (Dejours et al., 2018; Barboza et al., 2018; Fernández, Navarro, \& Fierro, 2018; Flores \& Moura, 2018; Moreira, Tibães, \& Brito, 2018; Amaral, Borges, \& Juiz, 2017; Souto et al., 2017; Giordano \& Felli, 2017; Ruza \& Silva, 2016).

O sofrimento, por outro lado, pode atuar como mobilizador para mudanças ou ser um fator de adoecimento. É por meio dele que as pessoas reelaboram e ressignificam suas vivências subjetivas (Dejours, Abdoucheli, \& Jayet, 2015; Dejours et al., 2018). Este pode ser despertado pelo medo, pelas distorções que o indivíduo tem de sua identidade, pelas diferentes experiências de cada trabalhador e pelas relações de trabalho complexas (Cortez et al., 2017; Hoffmann et al., 2017; Leite \& Nogueira, 2017; Souto et al., 2017; Dejours et al., 2018, Tundis \& Monteiro, 2018; Tundis et al., 2018; Facci; Urt, \& Barros, 2018; Fernández et al., 2018).

Observando o trabalho na docência, especialmente no ensino universitário, investigadores (Dejours et al., 2018; Fernández et al., 2018) enfatizam que há um cenário de intensificação e de precarização nas relações de emprego, o que pode gerar repercussões na identidade pessoal e profissional. Para a Organização Internacional do Trabalho (OIT, 2016), a profissão docente é uma das mais estressantes, com forte incidência de transtornos desencadeados pelo sofrimento, como a Síndrome de Burnout, entre outros tipos de adoecimento.

No que tange ao trabalho na docência universitária, especialmente na pós-graduação, estudos nacionais e internacionais (Ruza \& Silva, 2016; Souto et al., 2017; Fernández et al., 2018; Ferreira, Ferenc, \& Wassem, 2018; Hoffmann et al., 2018; Moreira, Tibães, \& Brito, 2018; Novaes, Werneck, Cesse, Goldbaum, \& Minayo, 2018) constatam que o processo de trabalho docente implica uma boa performance diante das demandas institucionais, estar sempre melhorando a quantidade e a qualidade da produção científica, entre uma diversidade de outras atividades de ensino, pesquisa e extensão. Nesse cenário, comumente exige-se que os docentes fomentem a capacidade crítica e reflexiva do discente e busquem inovação dos métodos. Tantas exigências resultam na intensificação do trabalho na pós-graduação stricto sensu.

O Brasil conta com 2.138 programas de pós-graduação com mestrado e doutorado; 1.338 mestrados; 739 mestrados profissionais; 81 doutorados $\mathrm{O}$ número estimado de docentes é de 80.772 permanentes, sendo 18.135 colaboradores, 1.380 visitantes, totalizando 100.287 docentes no stricto sensu brasileiro (Coordenação de Aperfeiçoamento de Pessoal de Nível Superior, 2019). Assim, os docentes da pós-graduação representam um número importante de trabalhadores no país.

Nesse sentido, questionou-se: como o trabalho na docência na pós-graduação stricto sensu interfere no prazer e sofrimento dos docentes? Assim, objetivou-se identificar as situações geradoras de prazere sofrimento no trabalho docente na pós-graduação stricto sensu.

\section{Método}

Trata-se de um estudo descritivo, com abordagem quanti-qualitativa, uma vez que segmentadas, são insuficientes para compreender o contexto investigado.

\section{Participantes}

Os participantes foram docentes dos sete programas stricto sensu de diferentes áreas, reunidos em uma universidade catarinense, sendo eles: (1) Mestrado e Doutorado em Ciências da Saúde; (2) Mestrado em Ciências Contábeis e Administração; (3) Mestrado em Educação; (4) Mestrado em Direito; (5) Mestrado em Tecnologia e Gestão da Inovação; (6) Mestrado e Doutorado em Ciências Ambientais e (7) Mestrado Profissional em Políticas Sociais e Dinâmicas Regionais.

Atendeu-se os seguintes critérios de inclusão: ser docente permanente de curso stricto sensu e estar atuando por no mínimo um ano completo. Foram excluídos os docentes afastados por qualquer motivo no período da coleta de dados. Os sete programas contavam, no período de coleta dos dados, com 82 docentes. Destes, 67 atenderam aos critérios, 47 aceitaram participar da primeira etapa (quantitativa), e dentre estes 14 docentes foram sorteados, sendo dois de cada programa, para segunda etapa (qualitativa).

\section{Instrumentos}

Na etapa quantitativa utilizou-se um Questionário de Dados Sociolaborais e de Condições de Saúde elaborado para o estudo (inclui idade, tempo de formação profissional, experiência docente e na pós-graduação, além de dados sobre organização e jornada de trabalho). Em seguida, utilizou-se o Inventário sobre Trabalho e Riscos de Adoecimento (ITRA) (Mendes \& Ferreira, 2007). Este instrumento tem como objetivo mensurar modalidades distintas e independentes de representações dos respondentes, relativas ao mundo do trabalho. Sua validação psicométrica é realizada com base na técnica de análise fatorial, partindo-se do pressuposto de que os riscos de adoecimento são influenciados por diversas dimensões, compostas por mais de um fator, e que são interdependentes. Por isso, utiliza-se o método PAF (Principal Axis Factoring) de análise, rotação oblimin, ou seja, modelo de rotação ponderada, com análise de correlação para cada uma das escalas e de confiabilidade (Mendes \& Ferreira, 2007). Suas representações se estruturam em quatro categorias: (1) Descrição do contexto de trabalho: são representações relativas à organização, às relações socioprofissionais e às condições do trabalho. Essa categoria é avaliada pela Escala de Avaliação do Contexto de Trabalho (EACT); (2) Descrição das exigências: são representações relativas ao custo físico, cognitivo e afetivo do trabalho. Essa categoria é avaliada pela Escala de Custo Humano no Trabalho (ECHT); (3) Descrição do sentido do trabalho: são representações relativas às vivências de prazer e de sofrimento no trabalho. Essa categoria é avaliada pela Escala de Indicadores de Prazer e Sofrimento no Trabalho (EIPST); (4) Descrição dos efeitos do trabalho para a saúde: são representações relativas à consequências em termos de danos físicos e psicossociais. Essa categoria é avaliada pela Escala de Avaliação dos Danos Relacionados ao Trabalho (EADRT) (Mendes \& Ferreira, 2007).

$\mathrm{Na}$ etapa qualitativa utilizou-se uma entrevista guiada por roteiro semiestruturado com questões relacionadas às características do trabalho e o prazer e sofrimento no trabalho. 


\section{Procedimentos de Coleta de Dados e Cuidados Éticos}

Para coleta de dados na primeira etapa os instrumentos foram enviados via aplicativo Google Forms no e-mail institucional de cada participante e/ou entregue em cópia física, como tentativa de maior alcance de participantes. Nessa etapa apresentou-se o estudo e solicitou-se a concordância por meio do Termo de Consentimento Livre e Esclarecido.

Os participantes foram consultados quanto ao local e horário de disponibilidade para a realização da segunda etapa, cujas entrevistas duraram em média 30 minutos, foram audiogravadas com a autorização dos participantes e posteriormente, transcritas na íntegra. O quantitativo de entrevistas foi definido seguindo o critério de saturação, ou seja, quando a coleta deixou de agregar novas informações (Minayo, 2017).

O período de coleta de dados ocorreu entre os meses de outubro de 2018 e março de 2019 e a pesquisa foi avaliada e aprovada pelo Comitê de Ética em Pesquisa (parecer n. 2.799.056/2018). Para resguardar o sigilo e o anonimato dos participantes, os docentes, inclusive aqueles que eram coordenadores dos programas, estes foram identificados com nomes de pedras.

\section{Procedimentos de Análise dos Dados}

Para a análise dos achados do ITRA, seguiu-se a análise pré-estabelecida de para cada Escalas (Mendes \& Ferreira, 2007). Para os dados emergidos na EACT, sobre a organização do trabalho (11 itens), condições de trabalho (10 itens) e relações socioprofissionais (10 itens), utilizou-se eigenvalues (autovalores de um conjunto de dados, que permitem conhecer de que forma as variâncias da matriz de correlações estão distribuídas) de 1,5, variância total de 38,46\%, Teste de Kaiser-Meyer-Olkin (KMO - testa a identificação do modelo de análise fatorial, testando a consistência geral dos dados) de 0,93 e correlações acima de 0,25. A EACT é de cinco pontos (1 - nunca; 2 - raramente; 3 - às vezes; 4 - frequentemente; 5 - sempre). É construída com itens negativos e sua análise foi feita por fator e com base em três níveis (acima de 3,7 = avaliação mais negativa, grave; entre 2,3 e 3,69 = avaliação mais moderada, crítico; abaixo de 2,29 = avaliação mais positiva, satisfatório), considerando um desvio padrão em relação ao ponto médio. Assim, considera-se como resultado para o contexto de trabalho. Posteriormente a realização das análises de cada fator, o conjunto dos dados é interpretado, a depender dos níveis de avaliação que predominaram, como satisfatórios, críticos e grave (Mendes \& Ferreira, 2007).

A ECHT é composta por três fatores, custo físico (10 itens), cognitivo (10 itens) e afetivo (12 itens). Apresenta eigenvalue maior que 2 , variância total de 44,98\%, KMO de 0,91 e $50 \%$ das correlações acima de 0,30 . A Escala é de 5 pontos (1 - nunca; 2 - pouco exigido; 3 - mais ou menos exigido; 4 - bastante exigido; 5 - totalmente exigido) e assim como a primeira escala, a análise deve ser feita por fator e com base em três níveis, considerando um desvio padrão em relação ao ponto médio. Ainda, tem-se a EIPST, a qual é composta por quatro fatores: dois para avaliar o prazer; realização profissional e liberdade de expressão (totalizam 18 itens) e dois para avaliar o sofrimento no trabalho; falta de reconhecimento e liberdade de expressão (totalizam 15 itens), com eigenvalues de 1,0 variância total de 59,80\%, KMO de 0,92 e 50\% das correlações acima de 0,30 . É uma escala de sete pontos $(0$ - nenhuma vez; 1 - uma vez; 2 - duas vezes; 3 - três vezes; 4 - quatro vezes; 5 - cinco vezes; e 6 - seis ou mais vezes), e tem por objetivo avaliar nos últimos seis meses a ocorrência das vivências dos indicadores de prazer-sofrimento. Para os fatores do prazer, considerando que os itens são positivos, a análise é diferente das escalas anteriores. Deve ser feita também, por fator e classificada em três níveis diferentes (acima de 4,0=avaliação mais positiva; satisfatório; entre 3,9 e 2,1=avaliação moderada, crítico; abaixo de 2,0 = avaliação para raramente, grave) com um desvio padrão para cada um. Para os fatores do sofrimento, considerando que os itens são negativos a análise deve ser feita em níveis específicos (acima de 4,0 = avaliação mais negativa, grave; entre 3,9 e 2,1=avaliação moderada, crítico; abaixo de 2,0 = Avaliação menos negativa, satisfatório) (Mendes \& Ferreira, 2007).

A quarta e última escala, a EADRT, analisa os danos físicos (12 itens), psicológicos (10 itens) e sociais (7 itens). A Escala de 7 pontos ( 0 - nenhuma vez; 1 - uma vez; e assim sucessivamente, até 6 - seis ou mais vezes) objetiva avaliar nos últimos três meses os danos provocados pelo trabalho. O ponto médio dessa escala, embora matematicamente, seja 3,0 para fins deste inventário, é desdobrado em dois intervalos com variação de um desvio padrão (acima de 4,1=avaliação mais negativa/presença de doenças ocupacionais; entre 3,1 e 4,0=avaliação moderada/grave; entre 2,0 e 3,0 = avaliação moderada/crítico; abaixo de 1,9 = avaliação mais positiva/suportável) (Mendes \& Ferreira, 2007).

Os dados quantitativos foram analisados com auxílio do Statistical Package for the Social Sciences (SPSS), versão 21.0. Para comparar médias foram realizados os testes t-student ou Análise de Variância (ANOVA), bem como Tukey. Para avaliar a associação entre as variáveis contínuas e ordinais foram empregados os testes de correlação de Pearson ou Spearman (nível de significância adotado foi de $5 \%$, considerando $p<0,05$ ).

Para a análise das entrevistas foi utilizada a Análise Temática (Bardin, 2016), ocorrendo em três etapas: pré-análise, exploração do material e tratamento dos resultados obtidos, que foram interpretados à luz do referencial da Psicodinâmica do Trabalho. As categorias utilizadas nesse manuscrito foram: "Prazer no trabalho do docente na pós-graduação" e "Sofrimento no trabalho do docente na pós-graduação.

\section{Resultados}

Os participantes eram, na maioria, homens (61,7\%), com companheiros $(n=42 / 89,4)$, com filhos $(n=34 / 72,3)$, com em média 46,5 anos de idade (desvio padrão de 10,1), formados em média há 17 anos, atuavam em média 15 anos na docência, mas somente quatro anos em média, na pós-graduação. Outras características dos docentes participantes estão detalhadas na Tabela 1.

Tabela 1

Caracterização dos participantes e dados laborais dos docentes (n=47), Chapecó, 2019.

\begin{tabular}{lc}
\hline \multicolumn{1}{c}{ Variáveis } & $\begin{array}{c}\text { Participantes } \\
(n=47) n(\%)\end{array}$ \\
\hline Área de formação & $5(10,6)$ \\
$\quad$ Engenharia & $12(25,5)$ \\
$\quad$ Ciências Sociais Aplicadas & $9(19,1)$ \\
$\quad$ Ciências da Saúde & $13(27,7)$ \\
Ciências Humanas & $5(10,6)$ \\
$\quad$ Ciências Biológicas & $2(4,3)$ \\
$\quad$ Ciências Agrárias & $1(2,1)$ \\
$\quad$ Ciências Exatas e da Terra & 40 \\
Número de horas de jornada laboral & 28 \\
Carga horária mensal para o PPG (horas) & 10 \\
Carga horária mensal de atividades na graduação (horas) & 5,5 \\
Número de orientações stricto sensu concluídas & 4 \\
Número de orientações stricto sensu em andamento & $7(14,9)$ \\
Ocupa cargo de coordenação de curso & $11(23,4)$ \\
Possui outro emprego - $n$ (\%) &
\end{tabular}

Nota. Legenda: $n=$ quantitativos $\%=$ frequência. Fonte: elaboração dos autores (2019). 
Identificou-se com a EACT, que quanto maior é o tempo de formação profissional, mais negativa é a avaliação que os docentes têm do domínio da Organização do Trabalho $(p=0,022)$ e maior é a percepção de danos físicos ocasionados pelo trabalho $(p=0,011)$.

Constatou-se associação significativa entre apresentar sintoma que sugere alteração de saúde física ou emocional e o domínio de Organização do Trabalho $(p=0,001)$, sendo esse achado ilustrado na Figura 1.

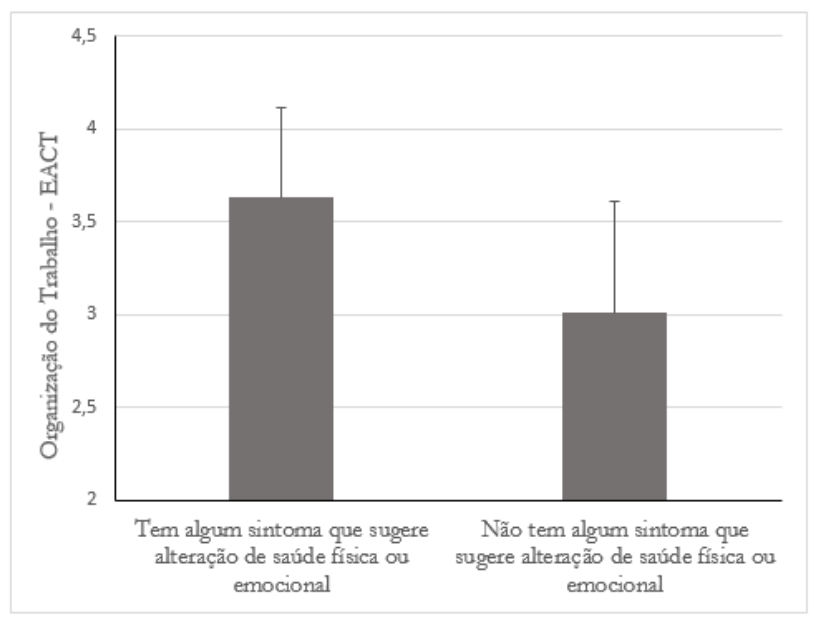

Figura 1. Associação entre apresentar algum sintoma que sugere alteração de saúde física ou emocional e o domínio de Organização do Trabalho da escala EACT, Chapecó, 2019. Fonte: elaboração dos autores (2019).

Cabe apresentar que para superar as condições adversas no trabalho, 29,8\% ( $\phi=0,004)$ dos docentes fazem uso de medicamentos, especialmente analgésicos e ansiolíticos.

$\mathrm{Na}$ tabela 2, reúnem-se achados significativos da EIPST, os quais revelaram que a quantidade de horas de jornada laboral e atuar como coordenador de curso são elementos que influenciaram a realização profissional e a liberdade de expressão dos docentes do stricto senso. Por outro lado, a titulação foi associada ao sentimento de falta de reconhecimento entre os docentes.

$\mathrm{Na}$ etapa qualitativa foi possível aprofundar alguns achados da etapa quantitativa. A Figura 2 ilustra as categorias e subcategorias da análise dos achados qualitativos.
Prazer para mim é eu vir trabalhar acreditando no que eu faço, sendo verdadeira naquilo que eu faço, passando uma educação que seja transformadora [...] (Berilo).

Eu gosto de ser professora, eu gosto de estar com os estudantes de ver a discussão deles, o crescimento, eu gosto muito de orientar [...] me dá uma alegria muito grande, porque eu noto o estudante se transformando (Alexandrita).

Notou-se o reconhecimento como gerador de prazer na esfera organizacional, a captação de recursos de fontes de fomento, identificar-se com a profissão/gostar do que faz, bem como a produção bibliográfica:

E quando o seu trabalho é reconhecido, quando capta recursos de fonte de fomento para desenvolver aquela pesquisa que você vê que está fazendo sentido. Então são esses momentos que acabam trazendo prazer na prática da docência (Jade). A docência não é só a docência, não é só um trabalho que eu tenho. É um local onde eu posso realizar os meus sonhos e projetos de mundo, não só de vida pessoal (Água Marinha).

Prazer é também publicar; tu fica muito faceira né? (Alexandrita).

Noque se refere ao Sofrimento no trabalhododocenteno stricto sensu, as falas a seguir ilustram a alta demanda por produção científica, a intensificação do trabalho, a sobrecarga provocada pelo excesso de demandas, a burocratização e as fragilidades nas relações laborais:

Nem sempre eu consigo dar conta de ler com o tempo que eu quero. Porque às vezes a sensação que dá é que meu Deus! Eu só li e não produzi. Porque há uma demanda pela produção [sic] quantos A1, quantos A2, isso não é a gente que se coloca, é uma performatividade que está na CAPES [sic] (Alexandrita).

Gastar muito tempo com questões burocráticas, reuniões que não chegam a nenhuma conclusão (Azurita).

Tabela 2

Fatores independentemente associados com a Escala de Indicadores de Prazere e Sofrimento no Trabalho (EIPST), Chapecó, 2019.

\begin{tabular}{|c|c|c|c|}
\hline Escalas & b (IC 95\%) & Beta & $p^{*}$ \\
\hline \multicolumn{4}{|l|}{ Realização Profissional } \\
\hline Número de horas de jornada laboral & $0,05(0,01$ a 0,09$)$ & 0,318 & 0,022 \\
\hline Ocupa cargo de coordenação de curso & $1,20(0,16$ a 2,24$)$ & 0,311 & 0,025 \\
\hline \multicolumn{4}{|l|}{ Liberdade de expressão } \\
\hline Número de horas de jornada laboral & $0,05(0,00$ a 0,10$)$ & 0,286 & 0,047 \\
\hline Ocupa cargo de coordenação de curso & $1,24(0,09$ a 2,39$)$ & 0,293 & 0,035 \\
\hline \multicolumn{4}{|l|}{ Falta de reconhecimento } \\
\hline Titulação & $0,71(0,00$ a 1,42$)$ & 0,258 & 0,049 \\
\hline $\begin{array}{l}\text { Você associa algum sintoma que sugere altera- } \\
\text { ção de saúde física ou emocional ao trabalho }\end{array}$ & $1,38(0,45$ a 2,31$)$ & 0,515 & 0,005 \\
\hline
\end{tabular}

Nota. $*$ Nível de significância 5\% ( $p<0,05)$. Fonte: elaboração dos autores (2019).

Os trechos de falas dos docentes ilustram as categorias associadas ao Prazer no trabalho do docente no stricto sensu:

Essa sensação de prazer é quando nós culminamos no término da atividade. [...] de você ver que você consegue agregar um conhecimento diferenciado, um conhecimento necessário para o mestrando e com a certeza de que ele vai fazer uso disso agora ou depois, durante a vida profissional (Safira).
Onde não tem espaço para diálogo brota o espaço do sofrimento, brota o espaço que a gente chama de rancor, brota a inimizade, brotam coisas desnecessárias, que muitas vezes com uma boa conversa elas seriam resolvidas [sic](Diamante).

Parte das fontes de sofrimento acima culminam no tempo reduzido para as relações extra universitárias, 


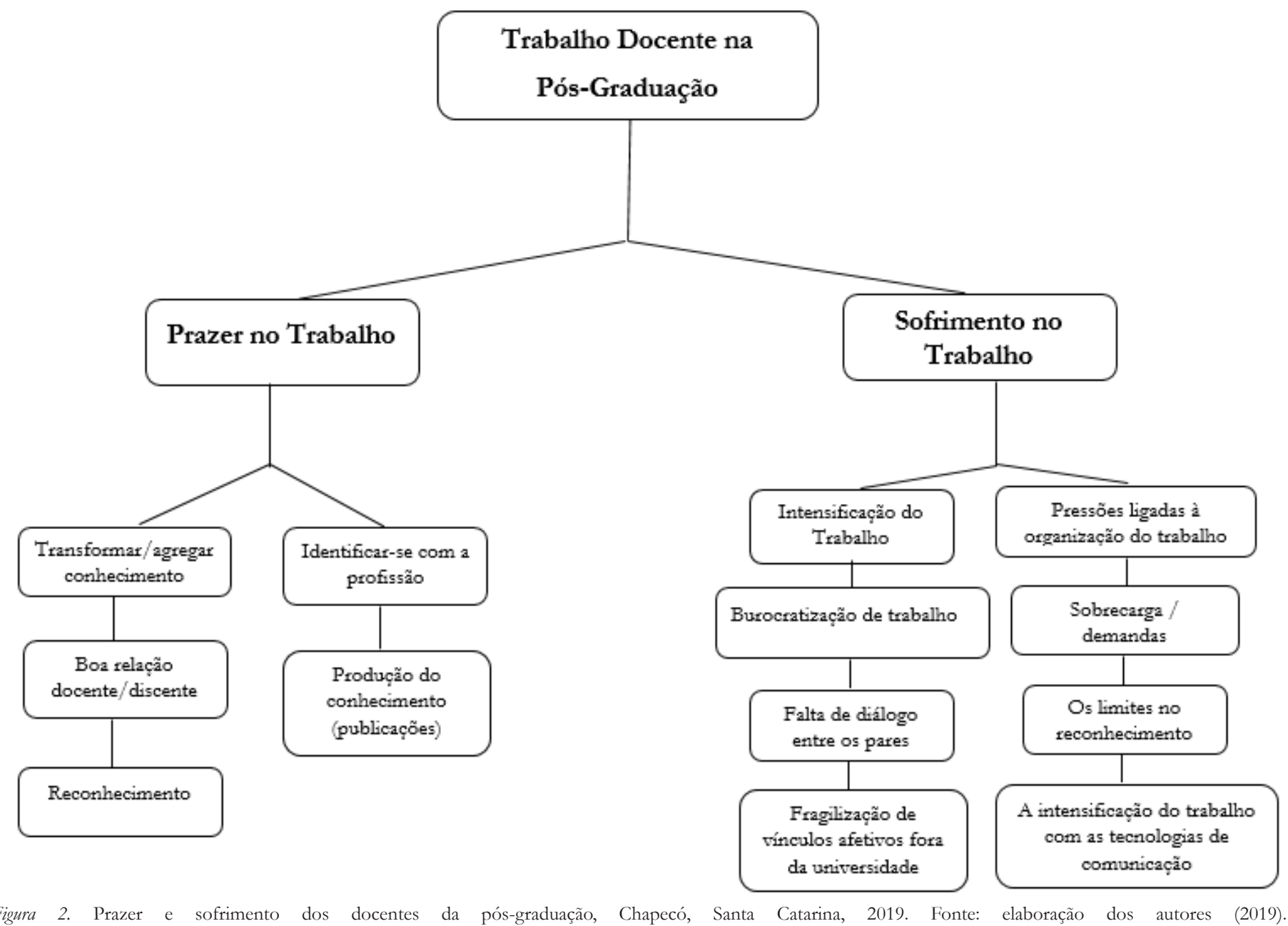

com a família e amigos, bem como para própria saúde:

A gente se dedica muito ao trabalho, deixa de lado a família, essa questão do exercício, da própria alimentação (Âmbar).

As pressões sofridas pelas exigências institucionais, de órgãos que fiscalizam e avaliam a pós-graduação são fatores que também perpassam o cotidiano docente:

Primeiro são aspectos das pressões externas e em segundo as questões das pressões internas, o que que nós produzimos aqui dentro. Do ponto de vista das pressões externas então tem uma conjuntura, política, econômica e cultural, que em certa medida vai colocando vários problemas para a universidade (Diamante).

Toda aquela questão de prazo, de a gente achar será que dei conta e isso gera angústia também para o professor (Azurita).

O reconhecimento, mencionado anteriormente como fonte de prazer, quando ausente, faz emergir o sofrimento.

A desvalorização, eu acho do papel do professor. Existe uma banalização, acho que pela sociedade, às vezes, até pelo aluno, que muitas vezes, nem agradece. Não que a gente tenha que fazer, pensando nesse sentido. [sic] Mas às vezes, o esforço do professor, ele não é valorizado, às vezes ele não é valorizado pelo aluno, às vezes ele não é valorizado pela instituição, ele não é valorizado pela sociedade, então isso, muitas vezes faz o professor de pós-graduação avaliar, até quanto vale a pena. Porque se não raro, a gente escuta, ah! Você só dá aula? (Azurita).
Por fim, os recursos tecnológicos de comunicação, as tecnologias de informação e comunicação (TIC), também tem intensificado o trabalho docente:

Então, em muitos casos, o professor não sabe onde que é a vida dele e onde que é o trabalho, porque se misturou. Ele está em casa, mas ele tem o Whatsapp, tem o notebook, ele tem o telefone, tem alguém que lhe chama em determinado momento e aquilo demanda uma atenção né, frente a uma determinada situação. Então isso é um grande problema (Diamante).

Cabe ainda destacar, entre os achados, que 46,8\% dos docentes identificam alterações em sua saúde física e emocional. Destes, 44,7\% relatam associação desses sintomas ao trabalho e 29,8\% fazem uso de medicamentos para superar as condições adversas do trabalho:

[sic] a razão de ter muitas atividades, me causa eu ter problemas de ansiedade, eu tenho problema de insônia, às vezes isso acontece. É um somatório de fatores, então eu uso medicações para dormir (Cristal).

[sic] desde que eu entrei na pós-graduação, efetivamente, o nível de cobrança aumentou, essa sensação de incapacidade, de você cumprir todas as coisas que você planejou [sic] repercutiu em aspectos como o meu sono, minha pressão, meu metabolismo, por exemplo, ganho de peso, e isso é uma questão associada ao estresse (Azurita).

Os achados revelam os danos à saúde do professor, entre eles o cansaço físico, o aumento de peso, resultados metabólicos, dores de cabeça e alteração da pressão arterial, os quais foram ilustrados pelos docentes como consequência de processos de trabalho 
exaustivos. Além disso, respostas somáticas como alteração de sono, preocupação, ansiedade e cansaço foram elencados como respostas advindas do desajustamento da organização do trabalho.

\section{Discussão}

Os docentes participantes do estudo podem ser identificados como adultos, em união estável e com filhos, os quais apresentam um bom tempo de formação e de exercício docente, porém, estão há menos de cinco anos na pós-graduação. Destacou-se, assim como em outros estudos (Amaral et al., 2017; Tundis \& Monteiro, 2018), que quanto maior é tempo de formação profissional, mais negativa é a avaliação da organização do trabalho. Esses achados sugerem que passados os anos, os docentes têm maior percepção da falta de domínio da organização do trabalho e poucas expectativas em transformá-la, especialmente, no que gera sofrimento.

Nesse contexto de mediação do sofrimento emergiu nos achados o uso de alguns medicamentos. Pesquisas apontam que a automedicação passa a ser uma forma rápida de alívio dos sintomas causados ou desencadeados pela docência e que docentes do ensino superior tendem a se automedicar, principalmente por apresentarem conhecimento mais amplo sobre os medicamentos, quando comparados a população em geral e maior autonomia sobre a própria saúde (Bataier, Pegorete, Lawall, \& Calvacant, 2017; Ruza \& Silva, 2016).

Evidenciou-se na EIPST que o aumento nos escores da Realização Profissional e da Liberdade de Expressão estão relacionados a um maior número de horas da jornada laboral e a ocupar um cargo de coordenação de curso, sendo o primeiro achado divergente de outros estudos (Dejours, Abdoucheli, \& Jayet, 2015; Hoffmann et al., 2018; Tundis \& Monteiro, 2018), os quais apontam que o tempo elevado em atividade aumenta a carga de trabalho, uma vez que elevam o desgaste mental, levam à exaustão e ao adoecimento dos docentes.

Constatou-se, no grupo estudado, que a dedicação ao stricto sensu reduz a quantidade de horas dos docentes na graduação, o que permite dedicação a outras atividades exigidas na pós-graduação. Esta particularidade parece proporcionar melhores condições para estudar junto com os discentes, para escrita, gerando prazer na atividade. Os participantes sinalizam ainda que contemplar a evolução dos estudantes e percebê-los como protagonistas do que estão fazendo é motivo de prazer no trabalho, bem como o reconhecimento pelas atividades formativas. O reconhecimento da qualidade do trabalho realizado é a resposta às expectativas subjetivas que quem trabalha carrega (Dejours, 2017; Ruza \& Silva, 2016) e, associado à gratificação e à mobilização da inteligência, está ligado à constituição da identidade das pessoas (Dejours, 2017).

Possuir o cargo de coordenação de curso sugere maior realização profissional e a liberdade de expressão, e quem não ocupa tem uma maior percepção de alteração de saúde física ou emocional. Corroborando a literatura, estudos (Amaral, Borges, \& Juiz, 2017; Moreira, Tibães, \& Brito, 2018) ilustram uma face ambígua, contraditória e fragmentada da coordenação, ao passo que o cargo pode atuar como potencializador para a formação dos estudantes e para a saúde em geral. Denota o acúmulo, a sobrecarga das atividades gerenciais e pode impactar negativamente na qualidade do trabalho, além de dificultar o desenvolvimento de atividades criativas.

Pesquisadores (Araújo et al., 2016) assinalam que o tempo de experiência profissional pode ser compreendido como um fator determinante para lidar adequadamente com as situações desgastantes no trabalho, visto que as vivências possibilitam a habilidade para a resolução de problemas. Entretanto, evidenciou-se que quanto maior a titulação e o tempo de formação profissional do docente, mais negativa é a avaliação nesse domínio, aspecto que pode ser melhor interpretado nas entrevistas, especialmente associado ao momento histórico e político do país, no qual a importância das atividades dos docentes universitários tem sido questionadas e cortes financeiros tem atingido a área da educação.

As entrevistas denotam que a docência se caracteriza por um espaço em que são experienciadas práticas que, ora despertam satisfação, ora desconforto, influenciadas pelo processo histórico e pela forma de ser e "sentir" (Cortez et al., 2017). Assim, o prazer e o sofrimento são compreendidos por aspectos afetivos, marcado pelas características individuais e pela percepção que cada um tem de si (Dejours, 2015, 2017).

A oportunidade de agregar conhecimento, fomentar o pensamento crítico e transformar a realidade emergiram como fontes de prazer no trabalho docente. Autores também enfatizam que a possibilidade de perceber o crescimento, a evolução, a transformação e a autonomia dos discentes são trazidas pelos profissionais como situações que ressignificam positivamente seu exercício (Giordano \& Felli, 2017; Moreira, Tibães, \& Brito, 2018).

A relação agradável entre docente e discente também, foi reconhecida como geradora de prazer. Estudos (Hoffmann et al., 2018; Moreira et al., 2018) revelam que tais relações são responsáveis por lapidar tanto o desenvolvimento docente quanto o discente. $\mathrm{O}$ prazer nesse cenário está relacionado ain$\mathrm{da}$, com o reconhecimento dos discentes, da comunidade científica, das fontes de fomento e da sociedade, que concebem o exercício da docência como um elemento fundamental ao desenvolvimento biopsicossocial dos seres humanos (Hoffmann et al., 2017; Ruza \& Silva, 2016; Troncon et al., 2018).

O reconhecimento da qualidade do trabalho realizado é a resposta às expectativas subjetivas que os profissionais carregam. Com o reconhecimento, as dúvidas, as dificuldades e o cansaço podem desaparecer diante do sentimento de ter contribuído para a construção coletiva e de constatar validado o lugar que se construiu entre os outros (Dejours, 2017). Para a Psicodinâmica, o reconhecimento é compreendido em dois sentidos: como gratidão pelas contribuições proporcionadas pelos trabalhadores no ajustamento da organização do trabalho e como constatação, conhecimento, revelação da realidade das contribuições dos trabalhadores à organização (Dejours et al., 2018). O reconhecimento do trabalho, ou mesmo da obra, pode ser reconduzido pelo sujeito ao plano da construção de sua identidade e isso se traduz afetivamente por um sentimento de alívio, de prazer, às vezes de leveza ou até de elevação (Dejours, 2017).Identificar-se com a profissão foi outro fator descrito como fonte de prazer no labor docente, consonante com a literatura (Cupertino, Garcia, \& Honório, 2015; Leite \& Nogueira, 2017; Souto et al., 2017; Tundis \& Monteiro, 2018).

Assim como em outas pesquisas (Amaral, Borges, \& Juiz, 2017; Troncon et al., 2018), as publicações são um fator importante de prazer entre os participantes. Evidenciou-se que a produção bibliográfica resulta em visibilidade e permite maior interação com os estudantes e colegas. Este último fator ainda, permite ampliar as atividades cooperativas.

Investigações (Cirani, Campanario, \& Silva, 2015; Moreira, Tibães, \& Brito, 2018; Noves et al., 2018) que discutem o sofrimento docente na pós-graduação apontam que esse cenário vem passando por inúmeras transformações nas últimas décadas. As cobranças das agências de fomento e avaliação, bem como as condições de trabalho a que os programas de pós-graduação estão sujeitos, desencadeiam sobrecarga, desconfiança e descontentamento.

Frente ao contexto, é possível melhor compreender os achados apresentados acerca as alterações na saúde física ou psíquica mencionadas pelos participantes da investigação. Estudos (Bataier et al., 2017; Facci, Urt, \& Barros, 2018; Fernández, Navarro, \& Fierro, 2018; Dejours, 2019) retratam, cada 
vez mais, essas alterações sintomáticas no cotidiano docente. Evidenciou-se que na pós-graduação a intensificação da carga de trabalho se eleva em decorrência da pressão em relação à produção científica e pela necessidade de executar várias tarefas, gerando consequentemente a intensificação do trabalho. A busca por uma matematização do trabalho em prol de uma suposta "eficiência e eficácia" tende a recair em vazios, em insignificância e essa excessiva valorização da quantidade de produção acadêmica tende a desconsiderar aspectos de qualidade (Hoffmann et al., 2018; Ruza \& Silva, 2016; Troncon et al., 2018). Além disso, as atividades administrativas e a burocratização do trabalho dificultam, cotidianamente, a fluidez dos processos laborais.

O sofrimento também se agrava pela ausência de espaços de diálogo, o que dificulta a tomada de decisão, causa descontentamento e gera sentimentos de desesperança em relação aos rumos da pós-graduação. É fundamental que este aspecto seja recuperado entre os pares, pois sem diálogo e escuta não há como se pensar a universidade em suas questões micro e macroestruturais (Araújo et al., 2016; Amaral, Borges, \& Juiz, 2017; Novaes et al., 2018; Tundis \& Monteiro, 2018). A escuta é fundamental nos processos de trabalho e contribui para repensar os arranjos da organização, potencializando a capacidade de ressignificar as práticas e fortalecer os laços simbólicos com o trabalho (Dejours, 2017, 2019).

A ampliação do tempo de trabalho, o aumento desenfreado da demanda por produção, além dos demais fatores da jornada prescrita, que excede a vida profissional e permeia a vida pessoal, acabam por fragilizar os vínculos afetivos, inclusive fora do espaço universitário (Ferreira, Ferenc, \& Wassem, 2018; Silveira \& Bendassolli, 2018). Outros pesquisadores complementam ao referir que a falta de tempo revela-se como um fator desconfortável que interfere na qualidade de vida e no desenvolvimento biopsicossocial dos docentes (Araújo et al., 2016).

As pressões ligadas à organização do trabalho e as metas impostas pelos órgãos que avaliam a pós-graduação vêm influenciando negativamente o exercício da profissão. Segundo os docentes e outras investigações, estas pressões geram tempo inadequado para pesquisas, prejudicam a profundidade e densidade teórica para avanço do conhecimento (Ferreira, Ferenc, \& Wassem, 2018; Ruza \& Silva, 2016).

As demandas e sobrecargas de trabalho que permeiam a pesquisa, ensino e extensão, verbalizadas e investigadas (Araújo et al., 2016; Ruza \& Silva, 2016) sugerem que essa categoria profissional está exposta a desafios que repercutem em adoecimento. Outras pesquisas (Amaral, Borges, \& Juiz, 2017) indicam que, muitas vezes, os três turnos do dia são ocupados e há uma prática comum de levar trabalho para ser realizado em casa.

Em relação aos limites do reconhecimento como fonte de desconforto, a Psicodinâmica do Trabalho o interpreta como um condutor a um vazio ontológico e ao sofrimento patogênico que, por vezes, transmuta em adoecimento físico e mental (Dejours et al., 2018). Sua ausência, percebida como suspeita de fracasso, passa a operar como o estigma de incompetência profissional, fomentando a demasiada competitividade.

Sobre o uso das Tecnologias de Informação e Comunicação (TIC), estas foram associadas ao sofrimento por não permitirem distanciamento das demandas laborais em momentos de descanso/lazer (Schuhmacher, Alves Filho, \& Schuhmacher, 2017). Essas tecnologias são ambíguas, pois por um lado, tensionam a disponibilidade de tempo dos profissionais, pressionando-os para a continua conectividade, o que resulta em aumento da carga de trabalho; por outro lado são um recurso para comunicação.

Diante do conjunto de dados expostos, a multicausalidade das fontes de prazer e a multifatorialidade de sofrimento na docência permitem compreender que tanto um quanto o outro são experienciados de maneira singular pelos docentes. $\mathrm{O}$ prazer sublimatório e o sofrimento criativo são possíveis quando há solidariedade, cooperação e reconhecimento do/no trabalho pelos pares e pela gestão. Em razão disso, prazer e sofrimento não podem ser compreendidos de forma reducionista, mas sim interpretados a partir de um somatório de vieses (Dejours et al., 2018).

\section{Considerações Finais}

O estudo notabilizou que existe uma linha tênue entre o prazer e o sofrimento entre docentes da pós-graduação stricto sensu. $O$ primeiro foi relacionado com a possibilidade de transformações da realidade, de agregar conhecimento, no reconhecimento pela docência e produtos publicados, e a identificação com o exercício da docência.

$O$ sofrimento foi marcadamente relacionado à intensificação, sobrecarga e burocratização do trabalho, à falta de diálogo entre os pares, fragilização dos vínculos afetivos fora da universidade, pressões ligadas à organização do trabalho, aos limites do reconhecimento e o contínuo trabalho gerado com as TIC. Além disso, evidenciou-se que uma parcela significativa de docentes apresenta alterações de saúde física e emocional, para as quais muitos recorrem a medicamentos.

É imprescindível detectar precocemente, os problemas associados ao trabalho, pensar em programas de promoção da saúde e prevenção do adoecimento, com prioridade às práticas de educação permanente que envolvam estratégias de convívio e valorizem os saberes e expectativas dos trabalhadores docentes. Nesse aspecto emerge um espaço para intervenções das instituições, as quais podem promover ações nessa direção.

Identificar as situações que suscitam o prazer e o sofrimento na docência na perspectiva da Psicodinâmica permitiu compreender a realidade multifacetada a que os profissionais estão expostos. Apesar das contribuições, compreende-se que o estudo tem limitações no que se refere à impossibilidade de agregar a participação de todos os docentes do universo pesquisado, o que se mostra um achado, pois muitos referiram a falta de tempo como justificativa para cancelamento ou recusa de participação.

Por fim, sugere-se que seja considerada a necessidade de compreender os docentes da pós-graduação integralmente, visto que suas respostas derivam de incompreensões, imposições e movimentos psicoafetivos gerados pela evolução dos seus conflitos inter e intrasubjetivos. É imprescindível a sensibilização dos pares e da gestão com o intuito de proporcionar aos profissionais processos de escuta e diálogo, com a finalidade de fortalecer as situações geradoras de prazer e minimizar o sofrimento.

\section{Referências}

Amaral, G. A., Borges, A. L., \& Juiz, A.P . M. (2017). Organização do Trabalho, Prazer e Sofrimento de Docentes Públicos Federais, Cadernos de Psicologia Social do Trabalho, 20(1), 15-28. https://doi.org/10.11606

Araújo, L. M. N., Rodrigues, C. C. F. M., Dantas, M. S. P., Santos, N. P., Alves, K Y. A., \& Santos, V. E. P. (2016). Estresse no cotidiano universitário: estratégias de enfrentamento de docentes da saúde, Revista Online de Pesquisa, 8(4), 4956-4964. https://doi. org/10.9789/2175-5361.2016.v8i4.4956-4964

Barboza, P. C., Pires, A. S., Júnior, E. F. P., Oliveira, E. B., Santo, T. B. E. S., \& Gallasch, C. H. (2018). Significado do trabalho: perspectivas de profissionais de enfermagem atuantes em unidades clínicas, Revista Rene, 19(1), 1-8. https://doi.org/10.15253/2175-6783.20181932819

Bardin, L. (2016). Análise de conteúdo. Edição Revista e Ampliada. São Paulo: Edições 70.

Bataier, V. S., Pegorete, T. R., Lawall, P. Z. M., \& Calvacanti, P. P. (2017). Automedicação entre docentes de nível superior, Revista Enfermagem Atual, 81(1), 11-18. https://doi.org/10.25248/REAS71 2017 
Cirani, C. B. S., Campanario, M. A., \& Silva, H. H. M. (2015). A evolução do ensino da pós-graduação senso estrito no Brasil: análise exploratória e proposições para pesquisa, Avalição, 20(1), 163-187. https://doi.org/10.590/ $\underline{\text { S1414-40772015000500011 }}$

Coordenação de Aperfeiçoamento de Pessoal de Nível Superior (CAPES) (2019). Recuperado de http://www.capes.gov.br/estatísticas.

Cortez, P. A., Souza, M. V. R., Amaral, L. O., \& Silva, L. C. A (2017). A saúde docente no trabalho: apontamentos a partir da literatura recente. Caderno de Saúde Coletiva, 25(1), 113-122. https://doi.org/10.1590/ 1414-462x201700010001

Cupertino, V., Garcia, F. C., \& Honório, L. C. (2015). Prazer e sofrimento na prática docente no ensino superior: estudo de caso em uma IFES mineira, Trabalho \& Educacão, 23(3), 101-116. ISSN 1516-9537

Dejours, C. (2015). A Loucura do Trabalho: estudo de psicopatologia do trabalho. São Paulo: Cortez. ISBN-10: 8524923466

Dejours, C. (2017). Psicodinâmica do Trabalho: Casos Clínicos. Porto Alegre: Dublinense. ISBN: 9788583180906

Dejours, C. (2019). Psicossomática e teoria do corpo. São Paulo: Blucher. ISBN: 9788521214496

Dejours, C., Abdoucheli, E., \& Jayet, C. (2015). Psicodinâmica do Trabalho: Contribuições da Escola Dejouriana à Análise da Relação Praẓer, Sofrimento e Trabalho. São Paulo: Editora Atlas S.A.

Dejours, C., Deranty, J. P., Renault, E., \& Smith, N. (2018). The Returno f Work in Critical Theory: self, society, politics. New York: Columbia University Press. ASIN: B077XNLWH4

Facci, M. G. D., Urt, S. C., \& Barros, A. T. F. (2018). Professor readaptado: a precarização do trabalho docente e o adoecimento. Psicologia Escolar e Educacional, 22(2), 281-290. https://doi.org/10.1590/2175-3539201802175546

Fernández, R. A., Navarro, E. M., \& Fierro, A. A. (2018). Buen o buena docente de universidad: Perspectiva del personal directivo de carrera y de los mismos grupos docentes. Revista Eletrónica Educare, 22(2), 1-27. https://10.15359/ ree.22-2.6

Ferreira, A. C. S. P., Ferenc, A. V. F., \& Wassem, J. (2018). Trabalho docente e avaliação da Capes: estranhamento e naturalização. Educação \& Realidade, 43(4), 1321-1341. https://doi.org/10.1590/2175-623684892

Flores, V. D. C., \& Moura, E. P. G. (2018). Significados de trabalho, prazer e sofrimento no ofício de agentes funerários. Revista Psicologia: Organizações e Trabalho, 18(1), 326-334. https://doi.org/10.17652/rpot/2018.1.13337

Giordano, D. P., \& Felli, V. E. A. (2017). Processo de trabalho dos docentes de enfermagem. Revista Latino-Americana de Enfermagem, 25(1), 1-8. https://doi. org/10.1590/1518-8345.1941.2946

Hoffmann, C., Zanini, R. R., Moura, G. L., Costa, V. M. F., \& Comoretto, E. (2017). Psicodinâmica do trabalho e riscos de adoecimento no magistério superior, Estudos Avançados, 31 (91), 257-276. https://doi.org/10.1590/ $\underline{\mathrm{s} 0103-40142017.3191019}$

Hoffmann, C., Marchi, J., Comoretto, E., \& Moura, G. L. (2018). Relações entre autoconceito profissional e produtivismo na pós-graduação, Psicologia ¿ Sociedade, 30(1), 1-10. https://doi.org/10.1590/1807-0310/2018v30167961

Leite, A. F., \& Nogueira, J. A .D. (2017). Fatores condicionantes de saúde relacionados ao trabalho de professores universitários da área da saúde: uma revisão integrativa. Revista Brasileira de Saúde Ocupacional, 42(6), 1-15. https:// doi.org/10.1590/2317-6369000010116

Mendes, A. M., \& Ferreira, M. C. (2007). Inventário de Trabalho e Riscos de Adoecimento - ITRA: instrumento auxiliar de diagnóstico de indicadores críticos no trabalho. Em A. M. Mendes (Org.), Psicodinâmica do Trabalho: teoria, método e pesquisa. São Paulo: Casa do Psicólogo.

Minayo, M. C. S. (2017). Amostragem e Saturação em Pesquisa Qualitativa consensos e controvérsias. Revista Pesquisa Qualitativa, 5(7), 01-12. ISSN: 2525-8222

Moreira, D. A., Tibães, H. B. B., \& Brito, M. J. M. (2018). Prazer e Sofrimento de docentes na pós-graduação stricto sensu em enfermagem. Revista Rene, 19(1), 1-8. https://doi.org/10.15253/2175-6783.20181933328

Novaes, H. M. D., Werneck, G. L., Cesse, E. A. P., Goldbaum, M., \& Minayo, M. C. S (2018). Pós-Graduação senso estrito em Saúde Coletiva e o Sistema Único de Saúde. Ciência \& Saúde Coletiva, 23(6) 2017-2025. https://doi. org $/ 10.1590 / 1413-81232018236.05612018$

Organização Internacional do Trabalho - OIT (2016). La promoción del trabajo decente en las cadenas mundiales de suministro en América Latina y el Caribe. Principales problemas, buenas prácticas, lecciones aprendidas y visión politica. Recuperado de https://www.ilo.org/sector/Resources/publications/ WCMS 503753/lang--pt/index.htm

Ruza, F. M., \& Silva, E. P. (2016). As Transformações Produtivas na Pós-graduação: O Prazer no Trabalho Docente está Suspenso? Revista Subjetividades, 16(1) 91-103. https://doi.org/10.5020/23590777.16.1.91-103

Schuhmacher, V. R. N., Alves Filho, J. P., \& Schuhmacher, E. (2017). As barreiras da prática docente no uso das tecnologias de informação e comunicação. Ciência e Educação, 23(3), 563-576. https://doi.org/10.1590/1516$\underline{731320170030002}$
Silveira, S. S., \& Bendassolli, P. F. (2018). Estratégias de conciliação trabalho-família de professores universitários em uma capital do Nordeste brasileiro, Revista Psicologia: Organização e Trabalho, 18(3), 422-429. https://doi. org/10.17652/rpot/2018.3.14299

Souto, B. L. C., Beck, C. L. C., Trindade, L. R., Silva, R. M., Backes, D. S., \& Bastos, R. A. (2017). O Trabalho Docente em Pós-Graduação: Prazer e Sofrimento. Revista de Enfermagem da UFSM, 7(1), 29-39. https://doi. org/10.5902/2179769222871

Troncon, L. E. A., Filho, A. P., Bollela, V. R., Borges, M. C., \& Pinto, M. P. P. (2018). Experiência de formação docente na pós-graduação e pesquisa em educação: projeto Capes Pró-Ensino na Saúde da Faculdade de Medicina de Ribeirão Preto, Universidade de São Paulo. Interface - Comunicação, Saúde, Educação, 22(1), 1493-04. https://doi.org/10.1590/1807-57622017.0025

Tundis, A. G. O., \& Monteiro, J. K. (2018). Ensino superior e adoecimento docente: um estudo em uma universidade pública. Psicologia da Educação, 46(1), 1-10. https://doi.org/10.5935/2175-3520.20180001

Tundis, A. G. O., Monteiro, J. K., Santos, A. S., \& Dalenogare, F. S. (2018). Estratégias de mediação no trabalho docente: um estudo em uma universidade pública na amazônia. Educação, 34(1), 1-23. https://doi.org/10.1590/0102$\underline{4698172435}$

\section{Informações sobre os autores:}

\section{Chancarlyne Vivian}

Avenida Sul Brasil, 1330, apto 101, Centro, Maravilha/SC, Brasil, CEP: 89874-000.

chancarlyne@unochapeco.edu.br

\section{Letícia de Lima Trindade}

letrindade@hotmail.com

Carine Vendruscolo

carine.vendruscolo@udesc.br 